\title{
Dying a "good death"
}

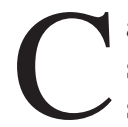

anada should legalize assisted suicide and voluntary euthanasia for competent adults who want to end their lives, even if they're not terminally ill, a Royal Society of Canada expert panel says.

Arguing that there is no philosophic distinction between assisted suicide or voluntary euthanasia, and withholding and withdrawal of life-sustaining treatment from competent adults, the panel says change is needed to help many Canadians realize their desire to die a "good death," at home.

To that end, Canada should join the seven jurisdictions - the Netherlands, Belgium, Luxembourg, Switzerland, Oregon, Washington State, and Montana - that have decriminalized assisted death, the Royal Society of Canada Expert Panel advocated in its report, End-of-Life Decision Making (www.rsc -src.ca/documents/RSCEndofLifeReport 2011_EN_Formatted_FINAL.pdf).

"If health care professionals not only can, but must, adhere to the wishes of a patient who no longer wishes to be treated, does it not stand to reason that they should also be permitted to assist that patient in dying? Those who deny this logical implication must drive a hard conceptual and moral line between action and omission. They must claim that it is worse to bring about a person's death than it is to omit an act so as to prevent a person's death. They must also defend the view that there is a moral distinction between killing and simply letting die."

Assisted suicide or voluntary euthanasia is also consistent with a constitutional "prima facie right to choose the time and conditions of one's death, and thus, as a corollary, to request aid in dying from medical professionals," as well as with the precepts of autonomous decision making in health care, the panel added.

The latter "requires that competent patients must not be subjected to treatment unless they have consented to it. That consent is subject to three condi-

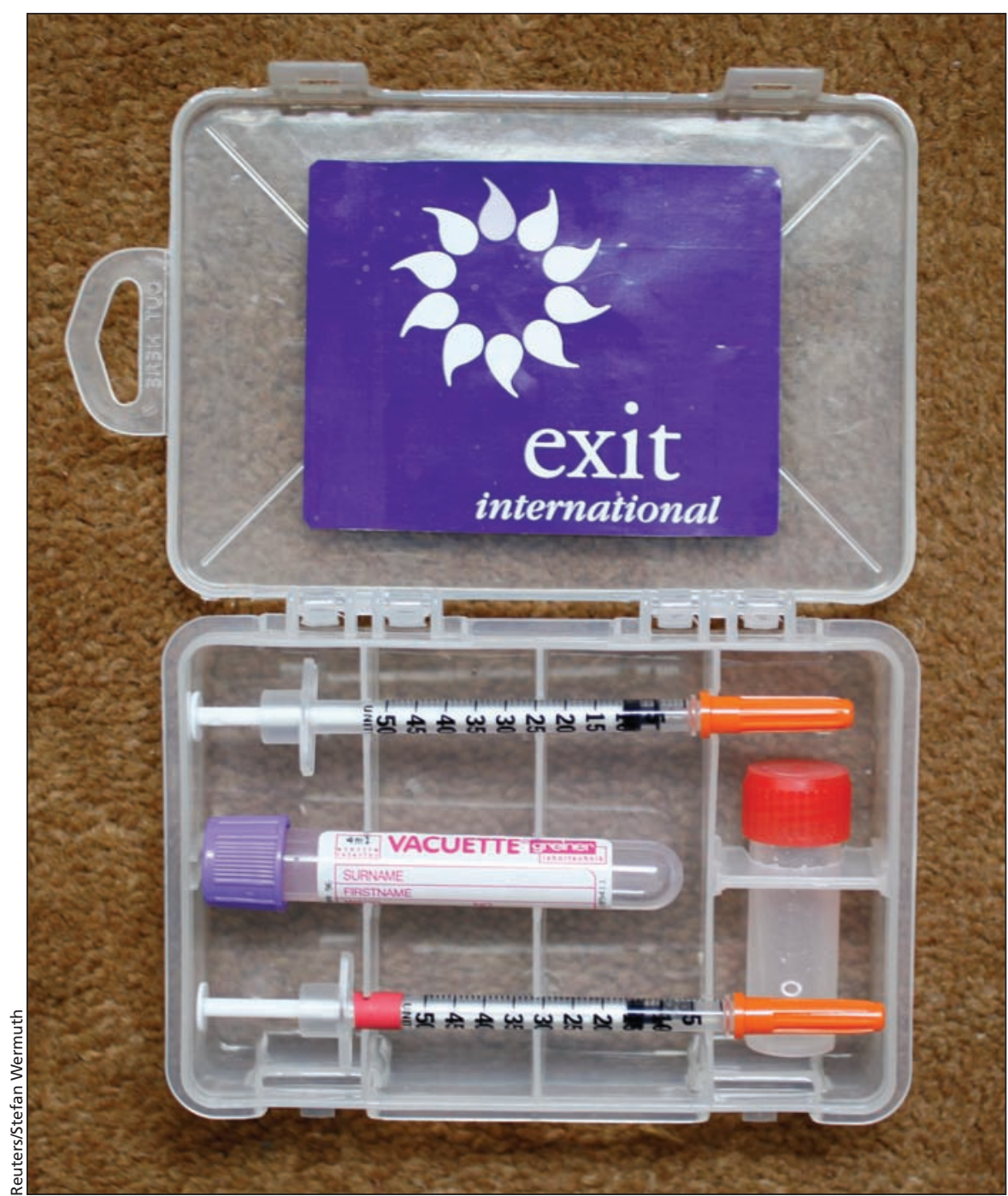

The "suicide kit" of reknowned euthanasia campaigner Dr. Philip Nitschke.

tions: first, it must be uncoerced; second, it must result from the decision making capacity of a cognitively competent individual; and third, it must be informed."

The report calls for sweeping revisions to the Criminal Code to allow assisted death under "carefully circumscribed and monitored circumstances" that include the age and competence of a person making a properly documented request.

As well, it urges reforms "across the spectrum of end-of-life law and policy" to improve palliative care and advance care planning, including recommendations that government set clear guidelines for the withdrawal or withholding of life-sustaining treatments, terminal sedation and the use of other treatments that may shorten a person's life.

Canada's current approach to end-oflife care is "chaos," and often fails to reflect the "great deal of importance [Canadians] ascribed to the idea individuals ought to be able to chart their own course in the way in which they lead their lives and the way in which their deaths are carried out," panelist 
and University of Montreal ethicist Daniel Weinstock told a press conference following release of the report in Ottawa, Ontario.

There's a major "disconnect" between the beliefs of Canadians and the illegality of counselling, aiding or abetting a person to commit suicide in Canada, added panel chair Udo Schuklenk, professor of philosophy and Ontario Research Chair in Bioethics at Queen's University in Kingston, Ontario. "We've found, over many years in fact, a very significant majority of the Canadian population appears to support a more permissive legislative framework for voluntary euthanasia and assisted suicide." individuals who "may be suffering greatly and permanently but are not imminently dying."

But it doesn't address how the proposed regime would handle requests for assisted death on the basis of emotional suffering, or whether persons with depression or other mental illnesses would be considered "competent" decision makers.

The panel would also limit assisted suicide or voluntary euthanasia to individuals who are competent, Weinstock said. "We have completely put aside the much more difficult and controversial question of how non-voluntary contexts should be handled."

The panel acknowledged concerns

\section{"If health care professionals not only can, but must, adhere to the wishes of a patient who no longer wishes to be treated, does it not stand to reason that they should also be permitted to assist that patient in dying?" - Royal Society of Canada Expert Panel in the report, End-of-Life Decision Making}

The report notes that jurisdictions which have decriminalized assisted suicide or voluntary euthanasia have typically imposed conditions, to wit: "the request must be voluntary; the request must be repeated (ie consistent over time); the request must be certified by a physician; the request must be wholly or at least in part carried out by a physician; [and] the person making the request must be legally competent."

Doctors should nevertheless have the right to refuse to take part in assisting death under such a regime, provided they refer competent individuals to willing practitioners, Weinstock said. "We're very aware that in the transition period ... this might take a while for physicians to get use to and some health care professionals may feel uneasy with the transition."

The report also says a diagnosis of "terminal illness" should not be required for access to voluntary euthanasia or assisted suicide as the term is "too vague" and there's no philosophic grounds for excluding that such reforms might lead to involuntary euthanasia of vulnerable people but argued in its report that such "prophesied undesirable social consequences are not sufficient to negate the right to choose assisted suicide and voluntary euthanasia."

While there will always be instances of abuse, "in actual fact, in societies that have kept assisted dying illegal there's a higher percentage of abuse," Schuklenk said. "The reason we suspect is that people are unable to talk honestly about what they want."

International evidence from the nations which have implemented decriminalization does not support the proposition, Schuklenk said.

The report indicates that "data from the Netherlands, Belgium, and Oregon show that the need for assisted death is only partly dependent on the quality and availability of palliative care" and that "even if it is the case that better palliative care would take away some of the need for assisted dying, it does not follow that society should wait until palliative care is optimized."
The report also argues for the creation of a regulatory regime, including a national oversight commission to "monitor and report annually and publicly on assisted suicide and voluntary euthanasia in Canada" as part of a bid to prevent "mistaken or intentional violations of the new law."

Until such time as the Criminal Code is amended, the panel called on provincial and territorial authorities to issue "guidance with respect to the exercise of prosecutorial discretion and to make clear the circumstances within which a prosecution for assisted suicide or voluntary euthanasia would not be in order."

In order to allay "misguided fear of liability," the report also calls on health care providers, regulators and prosecutors to "collaborate on the development of guidelines with respect to what they consider to constitute the Criminal Code standards of 'reasonable knowledge, skill and care' and 'wanton or reckless disregard' in the context of the provision of potentially life-shortening symptom relief."

Laws surrounding the withholding and withdrawal of treatment, terminal sedation and the use of other life-shortening pain treatments also need clarification, the report argued. As a result of current "confusion" surrounding legal rights and responsibilities, "it is possible that some legally valid refusals of treatment are not being respected and that potentially scarce medical resources are being wasted on care not consented to by patients or their legally authorized substitute decision-makers."

Other recommendations included:

- Discussions about end-of-life planning should be covered by health insurance plans.

- Administrative processes should be improved to ensure that advance directives and advance care plans are readily available to patients' caregivers, regardless of where they are getting care.

- Financial resources better used for palliative care should not be diverted into unwanted acute care.

- The scope of palliative care should be expanded beyond cancer. - Lauren Vogel, CMAJ

CMAJ 2011. DOI:10.1503/cmaj.109-4059 